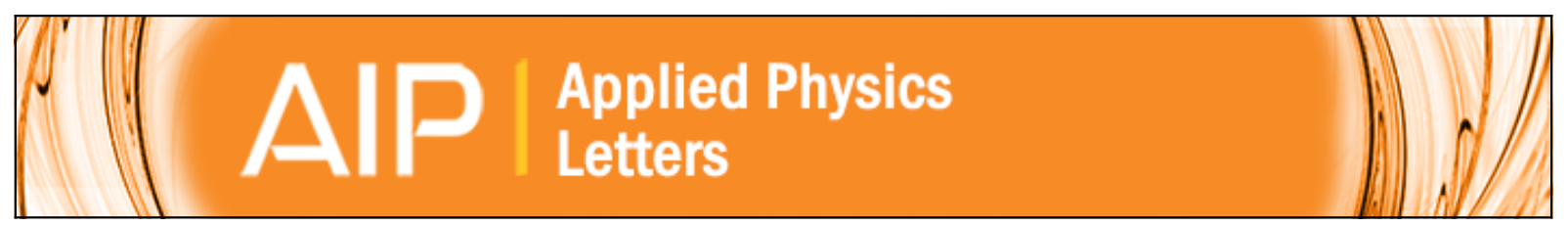

\title{
Phase contrast and operation regimes in multifrequency atomic force microscopy
}

Sergio Santos

Citation: Applied Physics Letters 104, 143109 (2014); doi: 10.1063/1.4870998

View online: http://dx.doi.org/10.1063/1.4870998

View Table of Contents: http://scitation.aip.org/content/aip/journal/apl/104/14?ver=pdfcov

Published by the AIP Publishing

\section{Articles you may be interested in}

Renormalization, resonance bifurcation, and phase contrast in dynamic atomic force microscopy

J. Appl. Phys. 110, 094314 (2011); 10.1063/1.3660745

Phase image contrast mechanism in intermittent contact atomic force microscopy

J. Appl. Phys. 108, 094311 (2010); 10.1063/1.3503478

Triple-frequency intermittent contact atomic force microscopy characterization: Simultaneous topographical, phase, and frequency shift contrast in ambient air

J. Appl. Phys. 108, 054901 (2010); 10.1063/1.3475644

Multiple impact regimes in liquid environment dynamic atomic force microscopy

Appl. Phys. Lett. 93, 093111 (2008); 10.1063/1.2976438

Multifrequency, repulsive-mode amplitude-modulated atomic force microscopy

Appl. Phys. Lett. 89, 113121 (2006); 10.1063/1.2345593

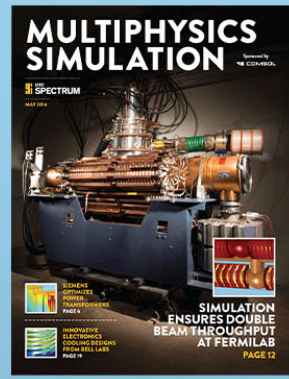

Free online magazine

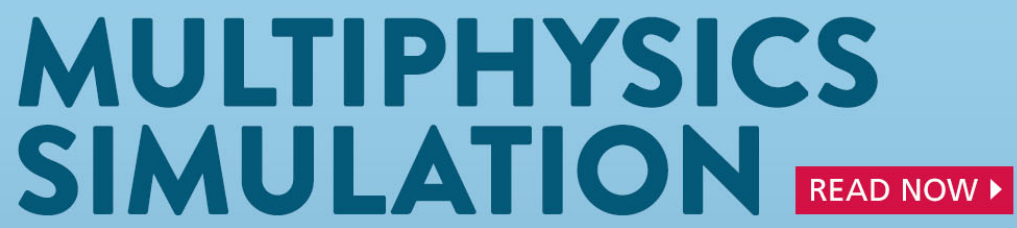




\title{
Phase contrast and operation regimes in multifrequency atomic force microscopy
}

\author{
Sergio Santos \\ Departament de Disseny i Programació de Sistemes Electrònics, UPC-Universitat Politècnica de \\ Catalunya Av. Bases, 61, 08242 Manresa (Barcelona), Spain
}

(Received 8 March 2014; accepted 30 March 2014; published online 8 April 2014)

\begin{abstract}
In amplitude modulation atomic force microscopy the attractive and the repulsive force regimes induce phase shifts above and below $90^{\circ}$, respectively. In the more recent multifrequency approach, however, multiple operation regimes have been reported and the theory should be revisited. Here, a theory of phase contrast in multifrequency atomic force microscopy is developed and discussed in terms of energy transfer between modes, energy dissipation and the kinetic energy and energy transfer associated with externally driven harmonics. The single frequency virial that controls the phase shift might undergo transitions in sign while the average force (modal virial) remains positive (negative). (C) 2014 AIP Publishing LLC. [http://dx.doi.org/10.1063/1.4870998]
\end{abstract}

Multifrequency atomic force microscopy (AFM) is an emerging $^{1,2}$ branch of AFM where two or more frequen$\operatorname{cies}^{3,4}$ are externally excited in order to map material composition, ${ }^{5-7}$ enhance resolution ${ }^{8}$ and sensitivity, ${ }^{9-11}$ and quantify material properties ${ }^{12-14}$ with gentle forces. The theory that controls the response of the cantilever while simultaneously exciting several frequencies and modes however is still emerging ${ }^{12,15,16}$ and might result complex. ${ }^{17,18}$ Here, possible mechanisms responsible for multiple regimes of operation in multifrequency AFM are discussed from the point of view of energy transfer in the presence of conservative and dissipative interactions. This is in line with recent reports discussing that multiple operation regimes can emerge in multifrequency AFM. ${ }^{17-19} \mathrm{We}$ report and discuss from a theoretical point of view and via numerical simulations that phase contrast arises from an interplay between energy dissipation and the kinetic energy, and energy transfer associated with the externally excited frequencies and eigenmodes.

The $M$ equations of motion ${ }^{20}$ that account for $M$ cantilever modes can be written in the following way: ${ }^{1}$

$$
\frac{k_{(m)}}{\omega_{(m)}^{2}} \ddot{z}_{(m)}(t)+\frac{k_{(m)}}{Q_{(m)} \omega_{(m)}} \dot{z}_{(m)}(t)+k_{(m)} z_{(m)}=F_{D}+F_{t s},
$$

where the subscript in brackets indicates mode $\mathrm{m}$ throughout. Then $\mathrm{k}_{(\mathrm{m})}, \mathrm{Q}_{(\mathrm{m})}, \omega_{(\mathrm{m})}$, and $\mathrm{z}_{(\mathrm{m})}$ are the spring constant, quality factor, natural frequency, and position of the $m$ eigenmode. $F_{D}$ is the term standing for the external driving forces. Two external forces with magnitudes $\mathrm{F}_{0(1)}$ and $\mathrm{F}_{0(2)}$ and acting near $\omega_{(1)}$ and $\omega_{(2)}$ have been added here as in standard bimodal AFM. ${ }^{1}$ The dynamics of the modes are coupled via the non-linear tip-sample force $\mathrm{F}_{\mathrm{ts}}$. The absolute position $\mathrm{z}$ is the sum of the $\mathrm{M}$ modes taken into account in the modal approximation

$$
z \approx \sum_{m>0}^{M} z_{(m)}
$$

or frequencies $z_{n}$

$$
z \approx z_{0}+\sum_{n>0}^{N} z_{n}=z_{0}+\sum_{n>0}^{N} A_{n} \sin \left(n \omega t+\phi_{n}\right),
$$

where the subscript without brackets stands for harmonic number $\mathrm{n}, \mathrm{z}_{0}$ is the mean deflection, and $\mathrm{A}_{\mathrm{n}}$ and $\phi_{\mathrm{n}}$ are the harmonic amplitudes and phases. The approximation implies that $\mathrm{N}$ is finite. Furthermore, the modes can also be decomposed into harmonic components

$$
z_{(m)} \approx z_{(m) 0}+\sum_{n>0}^{N} A_{(m) n} \sin \left(n \omega t+\phi_{(m) n}\right)
$$

where, $\mathrm{z}_{(\mathrm{m}) 0}$ is the mean deflection of mode $\mathrm{m}$; suffixes for mode $\mathrm{m}$ and harmonic number $\mathrm{n}$ are employed as $(\mathrm{m}) \mathrm{n}$ for amplitudes $\mathrm{A}_{(\mathrm{m}) \mathrm{n}}$ and phases $\phi_{(\mathrm{m}) \mathrm{n}}$. Then, the net energy entering $\left(\mathrm{E}_{\mathrm{T}(\mathrm{m})}<0\right)$ or leaving $\left(\mathrm{E}_{\mathrm{T}(\mathrm{m})}>0\right)$ a given cantilever mode $m$ can be written as

$$
E_{T(m)}=-\oint F_{t s} \cdot z_{m} d t
$$

where $\dot{\mathrm{z}}_{(\mathrm{m})}$ is the time derivative of $\mathrm{z}_{(\mathrm{m})}$ and $\mathrm{E}_{\mathrm{T}(\mathrm{m})}$ stands for net energy transfer (other than that lost to the viscous medium) per cycle via mode $\mathrm{m}$. One can refer to such expression as Energy Transfer. In this work, two mechanisms accounting for $\mathrm{E}_{\mathrm{T}(\mathrm{m})}$ are identified, namely, (1) energy irreversibly lost in the tip-sample junction from mode $m$ and (2) energy transfer from mode $m$ to any other modes. The first mechanism requires the presence of dissipative forces while the second does not. Another key definition in dynamic AFM is that of the tip-sample virial

$$
V_{(m)}=\frac{1}{T} \oint F_{t s} z_{(m)} d t
$$

where $V_{(m)}$ stands for tip-sample virial of mode $\mathrm{m}$ and $\mathrm{T}$ is the fundamental period. In general, $V_{(m)}$ might be positive or negative. For simplicity modes 1 and 2 , i.e., $\mathrm{m}=1$ and $\mathrm{m}=2$, are accounted for in this work as in standard bimodal AFM. ${ }^{1}$ A more common ${ }^{21,22}$ definition of (5) and (6) 
involves the harmonic terms only that coincide with, or lie near the, modal frequencies

$$
\begin{aligned}
E_{T(m) n} & =-\oint F_{t s} A_{(m) n} n \omega \cos \left(n \omega t+\phi_{(m) n}\right) d t \approx E_{T n} \\
& =\frac{n \pi k_{(m)} A_{0 n} A_{n}}{Q_{(m)}}\left[\sin \phi_{n}-\frac{A_{n}}{A_{0 n}}\right]
\end{aligned}
$$

where $\mathrm{m}$ can take the values 1 and 2 and the corresponding harmonic numbers $\mathrm{n}$ are 1 and 6 , respectively, and throughout. Furthermore, $\mathrm{A}_{0 \mathrm{n}}$ are the free amplitudes at $\omega(\mathrm{n}=1)$ and $6 \omega(\mathrm{n}=6)$ and it is assumed for simplicity that $\omega_{(1)} \approx \omega$ and $\omega_{(2)} \approx 6 \omega$. Similarly ${ }^{22}$

$$
\begin{aligned}
V_{(m) n} & =\frac{1}{T} \oint F_{t s} A_{(m) n} \sin \left(n \omega t+\phi_{(m) n}\right) d t \approx V_{n} \\
& =-\frac{1}{2} \frac{k_{(m)} A_{0 n} A_{n}}{Q_{(m)}} \cos \phi_{n} .
\end{aligned}
$$

Next we define the energy terms $E_{n}$ for harmonics $n=1$ $(\mathrm{m}=1)$ and $\mathrm{n}=6(\mathrm{~m}=2)$, respectively, as follows:

$$
E_{n}=K E_{n}+E_{T n}^{*},
$$

where $\mathrm{KE}_{\mathrm{n}}$ stands for kinetic energy and it is computed as the energy associated with the nth harmonic as

$$
K E_{n}=\frac{1}{2} k_{(m)} A_{n}^{2} .
$$

Furthermore, $\mathrm{E}_{\mathrm{Tn}}^{*}$ is related to $\mathrm{E}_{\mathrm{Tn}}$ in (7) by

$$
E_{T n}^{*}=\frac{E_{T n} Q_{(m)}}{2 \pi n} .
$$

Combining these expressions leads to the phase shifts of harmonics 1 and 6 (monitored in bimodal AFM) in terms of the inverse tangent and inverse cosine functions

$$
\phi_{n} \approx \tan ^{-1}\left[\frac{-E_{n}}{V_{n} Q_{(m)}}\right] \approx \cos ^{-1}\left[\frac{-2 V_{n} Q_{(m)}}{k_{(m)} A_{0 n} A_{n}}\right] .
$$

This expression is equivalent to those derived by others ${ }^{23,24}$ but its interpretation here leads to key results relating to energy transfer and phase contrast as discussed below. In standard AM AFM the fundamental phase shift $\phi_{1}$ might lie above or below $90^{\circ}$ in what defines two distinct force regimes, ${ }^{25}$ i.e., the attractive and the repulsive regimes, where the average tip-sample force $\mathrm{F}_{\mathrm{AV}}$ is attractive or repulsive, respectively. From now on, the average force $\mathrm{F}_{\mathrm{AV}}$ being negative or positive will be employed to define attractive and repulsive force regimes, respectively. The inverse tangent relationship in (12), however, suggest 4 possible combinations or regimes of operation at both harmonics $\mathrm{n}=1$ $(m=1)$ and $n=6(m=2)$, respectively. This follows from the fact that both $V_{n}$ in (8) and $E_{n}$ in (9) can, in principle, be positive or negative. A closer look at (12), however, indicates that the sign of the virial alone controls whether the phase lies above or below $90^{\circ}$ since the inverse cosine relationship depends on $V_{n}$ only. Then it also follows from the

inverse tangent relationship in (12) that it is a necessary condition that $\mathrm{E}_{1}>0(\mathrm{~m}=1)$ and that $\mathrm{E}_{6}>0(\mathrm{~m}=2)$. This is a main hypothesis in this work, and has some important implications:

(1) First, $\mathrm{E}_{\mathrm{T} 1}^{*}$ (and $\mathrm{E}_{\mathrm{T} 6}^{*}$ ) might be negative or positive implying that during the tip-sample interaction energy transfer might be positive or negative at $\mathrm{n}=1$ and/or $\mathrm{n}=6$. This is consistent for both conservative and dissipative interactions since no assumptions have been made in terms of the character of the forces. Also note that in monomodal AFM it is required that $\mathrm{E}_{\mathrm{Tn}}^{*}<0$ for $n>1$.

(2) Second, it necessarily follows from (12) that $\mathrm{KE}_{1}>-\mathrm{E}_{\mathrm{T} 1}^{*}\left(\mathrm{E}_{1}>0\right)$ and that $\mathrm{KE}_{6}>-\mathrm{E}_{\mathrm{T} 6}^{*}\left(\mathrm{E}_{6}>0\right)$.

(3) Third, for conservative interactions it is a necessary condition that $\mathrm{E}_{\mathrm{T}(1)}=-\mathrm{E}_{\mathrm{T}(2)}$ or, in terms of the monitored frequencies, $\mathrm{E}_{\mathrm{T} 1} \approx-\mathrm{E}_{\mathrm{T} 6}$.

The third point follows directly from the energy conservation principle. Note that the energy dissipated per cycle $\mathrm{E}_{\mathrm{dis}}$ can be written as

$$
E_{d i s}=E_{T(1)}+E_{T(2)} .
$$

Then, for a conservative system where $\mathrm{E}_{\mathrm{dis}}=0$ it follows that $\mathrm{E}_{\mathrm{T}(1)}=-\mathrm{E}_{\mathrm{T}(2)}$. For a more general system, where other eigenmodes are included $(M>2)$ energy transfers between the $M$ modes when $E_{\text {dis }}=0$. The energy transfer between modes 1 and 2 is illustrated in Fig. 1.

The expressions above are next compared to the results of numerical integration. In the long range $\mathrm{F}_{\mathrm{ts}}$ is defined by the Hamaker constant $\mathrm{H}$, the tip radius $\mathrm{R}$, and the tip sample distance $\mathrm{d}^{22}$

$$
F_{t s}(d)=-\frac{R H}{6 d^{2}} \quad \mathrm{a}_{0}<\mathrm{d},
$$

where $\mathrm{a}_{0}(\approx 0.165 \mathrm{~nm})$ is an intermolecular distance. The distance $\mathrm{d}$ and the tip position $\mathrm{z}$ are related via the cantilever separation $\mathrm{z}_{\mathrm{c}}$ since $\mathrm{d}=\mathrm{z}_{\mathrm{c}}+\mathrm{z}$.

For Fig. 2, the parameters are: $A_{01}=5 \mathrm{~nm}, A_{1}=4 \mathrm{~nm}$, $\mathrm{k}_{(1)}=2 \mathrm{~N} / \mathrm{m}, \mathrm{k}_{(2)}=80 \mathrm{~N} / \mathrm{m}, \mathrm{Q}_{(1)}=100, \mathrm{Q}_{(2)}=600, \mathrm{f}_{(1)}=70 \mathrm{kHz}$ $\left(\omega_{(1)}=2 \pi \mathrm{f}_{(1)}\right), \mathrm{f}_{(2)}=42 \mathrm{kHz}\left(\omega_{(2)}=2 \pi \mathrm{f}_{(2)}\right), \mathrm{H}=4.1 \times 10^{-19}$, $\mathrm{J}$ and $\mathrm{R}=5 \mathrm{~nm}$. Only the second mode phenomena corresponding with harmonic 6 are discussed in detail for

(a) mode 1

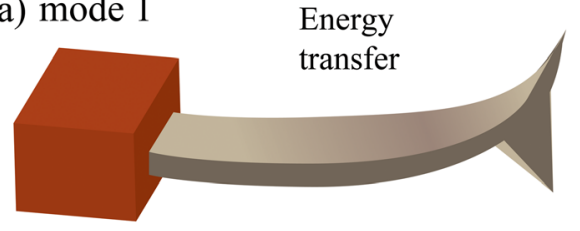

(b) mode 2

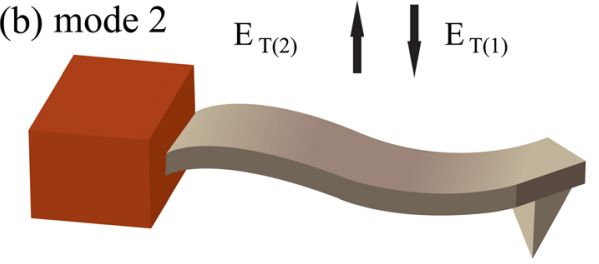

FIG. 1. Illustration of how energy might transfer between modes (a) 1 and (b) 2 . 
simplicity and because the corresponding channels $\mathrm{A}_{6}$ and $\phi_{6}$ provide $^{1}$ compositional contrast. With these parameters $\mathrm{d}$ always lied above $a_{0}\left(d>a_{0}\right)$ in the simulations. Thus, the example in Fig. 2 corresponds to bimodal AFM operated in the standard attractive regime where $\mathrm{F}_{\mathrm{AV}}<0$. Note also that in Fig. 2, $\mathrm{F}_{\mathrm{ts}}$ is conservative, i.e., $\mathrm{E}_{\mathrm{dis}}=0$. In the figure, the free amplitude of the second mode (sixth harmonic) $\mathrm{A}_{06}$ has been varied in the range $0.1-5 \mathrm{~nm}$ since this is characteristic of standard values in bimodal AFM. ${ }^{1,14,15}$ Fig. 2(a) shows variations of $\mathrm{KE}_{6}$ (squares) and $\mathrm{E}_{\mathrm{T} 6}^{*}$ (circles) with $\mathrm{A}_{06}$. The energies have been normalized with $6.2 \mathrm{keV}$. $\mathrm{KE}_{6}$ monotonously increases with $\mathrm{A}_{06}$, whereas $\mathrm{E}_{\mathrm{T} 6}^{*}<0$ throughout. The numerical values are $\mathrm{E}^{*}{ }_{\mathrm{T} 6}=-0.3,-1.7154,-2.5318$, $-2.9002,-3.0365$, and $-3.1318 \mathrm{eV}$ for $\mathrm{A}_{06}=0.1,1,2,3,4$, and $5 \mathrm{~nm}$, respectively. By comparing these results with $\mathrm{KE}_{6}=3.1,239.2,972.3,2211.6,3954.1$, and 6198.1, it follows that the condition $\mathrm{KE}_{6}>-\mathrm{E}_{\mathrm{T} 6}^{*}$ is satisfied. The normalized values of $\mathrm{E}_{6}$ (rhombuses) and $\mathrm{V}_{6}$ (crosses) are plotted in Fig. 2(b); $E_{6}>0$ and $V_{6}>0$ throughout with maxima of $6.2 \mathrm{keV}$ and $0.9 \mathrm{eV}$, respectively. In terms of the observable $\phi_{6}$ this implies that $\phi_{6}>90^{\circ}$ throughout (Fig. $2(c)$ ) in accordance with the prediction of (12). According to the simulations here, these results should be standard in bimodal AFM in the attractive regime where $\mathrm{F}_{\mathrm{AV}}<0$. That is, $\phi_{6}>90^{\circ}$ independently of $\mathrm{A}_{06}$. Furthermore, from the numerical results it was also verified that $\mathrm{E}_{\mathrm{T} 1} \approx-\mathrm{E}_{\mathrm{T} 6}$, and, more thoroughly, $\mathrm{E}_{\mathrm{T}(1)}=-\mathrm{E}_{\mathrm{T}(2)}$ exactly. In summary, in the attractive regime the three conditions above are satisfied according to the simulations here.

(a)

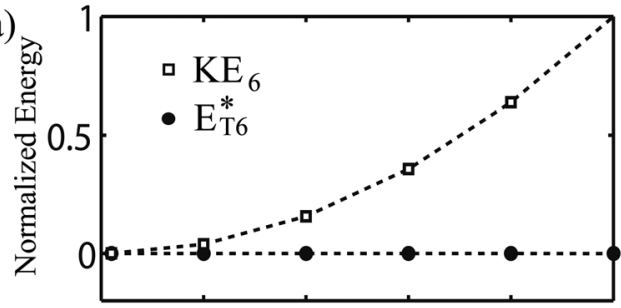

(b)

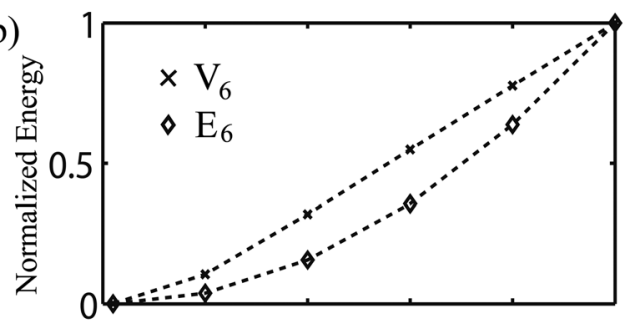

(c)

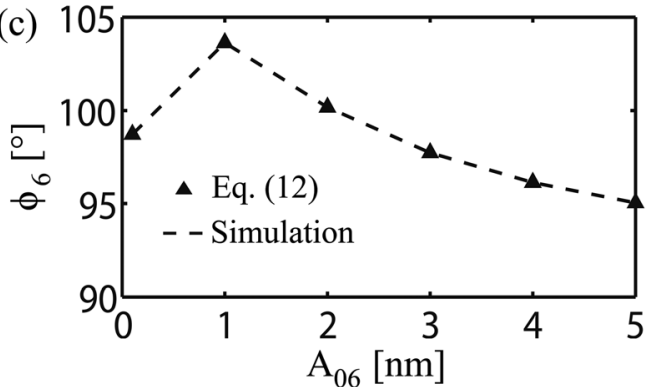

FIG. 2. Results of the experimental observables and expressions that can be computed from observables in bimodal AFM in the attractive regime as a function of second mode (sixth harmonic) free amplitude $\mathrm{A}_{06}$.
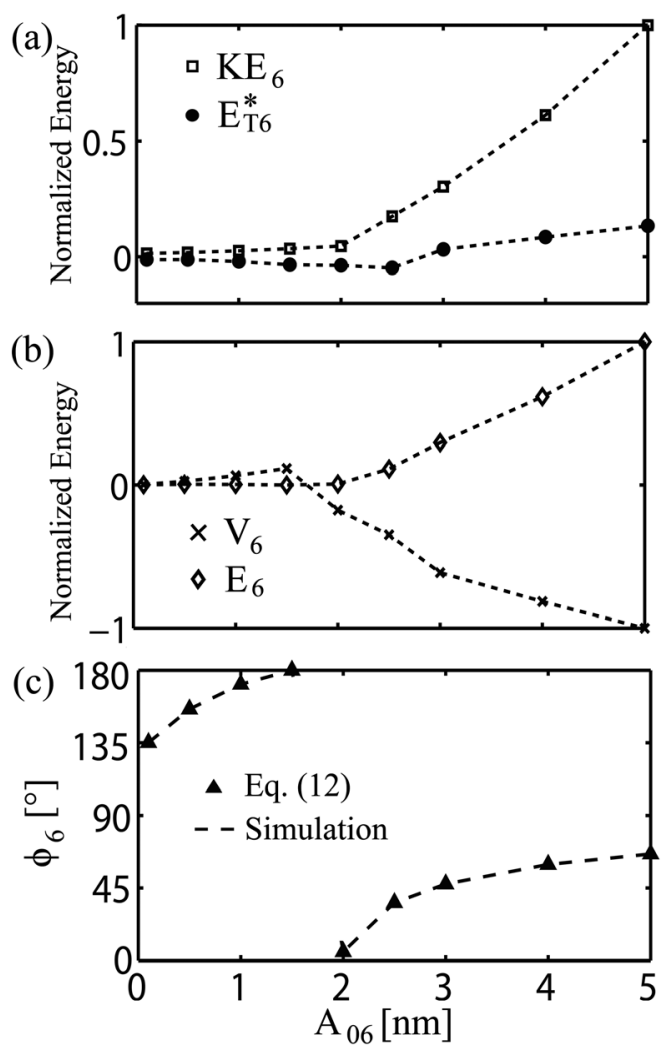

FIG. 3. Response (conservative forces only) of experimental observables and expressions that can be computed from observables in bimodal AFM in the repulsive regime as a function of second mode (sixth harmonic) free amplitude $\mathrm{A}_{06}$.
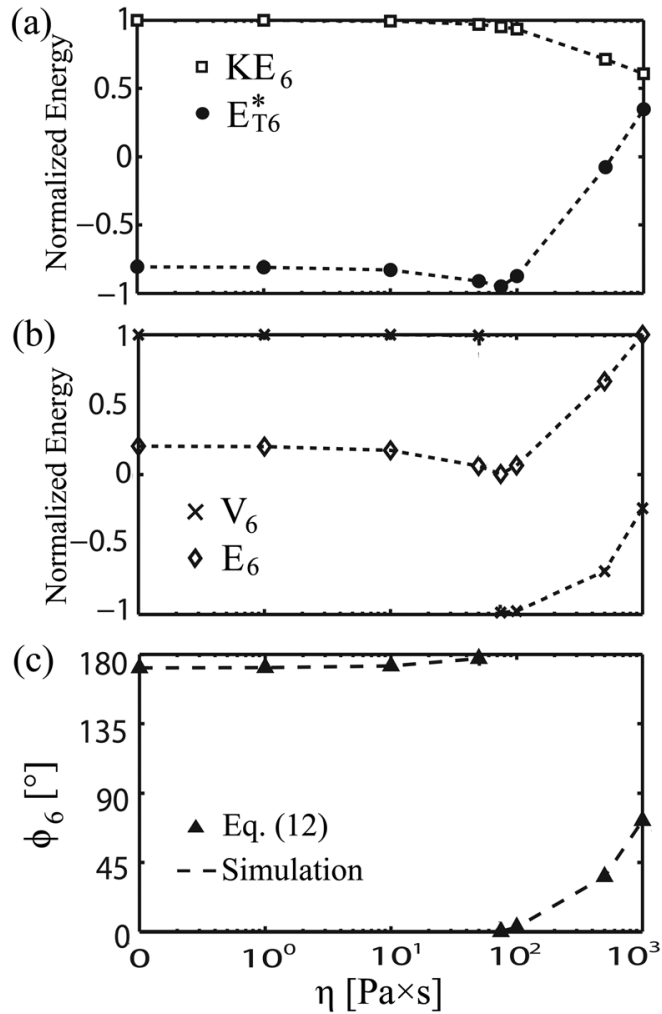

FIG. 4. Response (conservative and dissipative forces) of experimental observables and expressions that can be computed from observables in bimodal AFM in the repulsive regime as a function of viscosity $\eta$. 
TABLE I. Numerical values corresponding to the results in Fig. 3. The number of the equation employed is written in brackets in the first column.

\begin{tabular}{|c|c|c|c|c|c|c|c|c|c|}
\hline $\mathrm{A}_{06}[\mathrm{~nm}]$ & 0.1 & 0.5 & 1 & 1.5 & 2 & 2.5 & 3 & 4 & 5 \\
\hline $\mathrm{E}_{\mathrm{T}(1)}[\mathrm{eV}](5)$ & 5.93 & 8.86 & 11.29 & 12.82 & 13.88 & 17.78 & 19.03 & 20.1 & 20.51 \\
\hline $\mathrm{E}_{\mathrm{T}(2)}[\mathrm{eV}](5)$ & -5.93 & -8.86 & -11.29 & -12.82 & -13.88 & -17.78 & -19.03 & -20.1 & -20.51 \\
\hline $\mathrm{V}_{(1)}[\mathrm{eV}](6)$ & -10.18 & -9.84 & -9.53 & -9.33 & -9.18 & -8.59 & -8.39 & -8.22 & -8.16 \\
\hline $\mathrm{V}_{(2)}[\mathrm{eV}](6)$ & -0.01 & -0.12 & -0.31 & -0.56 & -0.86 & -1.7 & -2.24 & -3.17 & -4.05 \\
\hline $\mathrm{V}_{6}[\mathrm{eV}](8)$ & 0.02 & 0.12 & 0.32 & 0.56 & -0.86 & -1.71 & -3.00 & -3.99 & -4.89 \\
\hline $\mathrm{E}_{6}[\mathrm{eV}](9)$ & 10.22 & 33.45 & 29.22 & 0.43 & 49.01 & 739.69 & 1960.97 & 4079.16 & 6632.22 \\
\hline $\mathrm{KE}_{6}[\mathrm{eV}](10)$ & 83.89 & 107.22 & 150.24 & 203.35 & 269.69 & 1022.68 & 1773.73 & 3583.63 & 5853.96 \\
\hline $\mathrm{E}_{\mathrm{T} 6}^{*}[\mathrm{eV}](11)$ & -73.67 & -73.77 & -121.01 & -202.92 & -220.68 & -282.99 & 187.25 & 495.53 & 778.25 \\
\hline$\phi_{1}\left[{ }^{\circ}\right](12)$ & 35.11 & 37.76 & 40.03 & 41.49 & 42.51 & 46.45 & 47.74 & 48.85 & 49.24 \\
\hline$\phi_{6}\left[^{\circ}\right](12)$ & 135.05 & 155.86 & 171.32 & 179.93 & 5.42 & 35.85 & 47.46 & 59.61 & 66.13 \\
\hline $\mathrm{E}_{(2) 6}[\mathrm{eV}](17)$ & -10.52 & -33.73 & -29.48 & -0.64 & 48.85 & 739.73 & 1470.91 & 3263.71 & 5527.47 \\
\hline$\delta[\mathrm{nm}]$ & 1.07 & 1.15 & 1.23 & 1.3 & 1.37 & 1.57 & 1.66 & 1.79 & 1.88 \\
\hline $\mathrm{F}_{\mathrm{AV}}[\mathrm{pN}]$ & 86.67 & 84.18 & 82.38 & 81.63 & 81.46 & 76.79 & 74.91 & 73.04 & 72.19 \\
\hline
\end{tabular}

Next, bimodal AFM is operated in the repulsive regime where $\mathrm{F}_{\mathrm{AV}}>0$. For this purpose, a repulsive force ${ }^{22,25}$ is employed when $\mathrm{a}_{0} \leq \mathrm{d}$

$$
F_{t s}(d)=-\frac{R H}{6 a_{0}^{2}}+\frac{4}{3} E^{*} \sqrt{R} \delta^{3 / 2} \quad \mathrm{a}_{0} \geq \mathrm{d},
$$

where $\mathrm{d}$ and the tip-sample deformation $\delta$ are related by $\delta=\mathrm{a}_{0}-\mathrm{d}$. $\mathrm{E}^{*}(\approx 1 \mathrm{GPa}$ in this work $)$ is the effective Young's modulus in the contact and $\mathrm{A}_{06}$ has been varied from 0.1 to $5 \mathrm{~nm}$. The results are shown in Fig. 3 for: $\mathrm{A}_{01}=10 \mathrm{~nm}, \mathrm{~A}_{1}=10 \mathrm{~nm}$, and $\mathrm{H}=2.1 \times 10^{-20} \mathrm{~J}$ (all other parameters as in Fig. 2). The first thing to note from Fig. 3(a) is that $\mathrm{E}_{\mathrm{T} 6}^{*}$ (circles) goes from negative to positive for $\mathrm{A}_{06}=2.5-3 \mathrm{~nm}$. Physically this implies that for small values $\mathrm{A}_{06}$ or $\mathrm{KE}_{6}$ the energy transferred to $\mathrm{n}=6$ are positive. However, when $\mathrm{KE}_{6}$ (squares) is sufficiently large $(\sim 1 \mathrm{keV}$ in Fig. 3(a)) energy transfers from the 6th frequency (mode 2) to other frequencies. The numerical values are provided in Table I. Again Figs. 3(b) and 3(c) confirm that $\mathrm{E}_{6}>0$ and that $\mathrm{V}_{6}$ alone controls whether $\phi_{6}$ lies above or below $90^{\circ}$. In particular, $\mathrm{V}_{6}$ becomes negative in Fig. 3(b) for $\mathrm{A}_{06}=1.5-2 \mathrm{~nm}$ and the phase transition follows
(Fig. 3(c)). Numerical values of the corresponding $\delta$ and $\mathrm{F}_{\mathrm{AV}}$ are also given in Table I (discussed below).

As another test to the theory above, a dissipative force can be added in the contact region ${ }^{11,26}$

$$
F_{\text {dis }}(\delta)=-\eta(R \delta)^{1 / 2} \dot{\delta} \quad \delta>0 .
$$

The range of values given to the viscous coefficient $\eta$ in Fig. 4 is; $\eta=0,1,10,75,100,500$, and $1000 \mathrm{Pas}$ (x-axis). The rest of parameters are as in Fig. 3 except for $\mathrm{A}_{06}$ which is $1 \mathrm{~nm}$ throughout. Fig. 4(a) shows that $\mathrm{KE}_{6}$ (squares) decreases with increasing $\eta$ and dissipation $\left(\mathrm{E}_{\mathrm{dis}}\right)$. The energy transfer $\mathrm{E}^{*}{ }_{\mathrm{T} 6}$ (circles) goes from negative to positive with increasing $\eta$. Again $\mathrm{E}_{6}>0$ (Fig. 4(b) rhombuses) throughout (see Table II) and the sign of $\mathrm{V}_{6}$ (crosses) alone defines whether $\phi_{6}$ lies above or below $90^{\circ}$ (Fig. 4(c)).

Finally, we note an interesting physical observation. Namely, even if $\mathrm{V}_{6}>0$, and provided $\mathrm{F}_{\mathrm{AV}}>0$, the mode virial in (6) gives $\mathrm{V}_{(\mathrm{m})}<0$. This implies that $\phi_{6}$ does not follow from the sign of $\mathrm{V}_{(\mathrm{m})}$; see the corresponding numerical values in Table II and compare $\mathrm{V}_{(\mathrm{m})}, \mathrm{F}_{\mathrm{AV}}, \phi_{1}$, and $\phi_{6} . \mathrm{F}_{\mathrm{AV}}$ is also shown in Table I for the results in Fig. 3 where it can be seen that $\mathrm{F}_{\mathrm{AV}}$ decreases monotonously with increasing $\mathrm{A}_{06}$.

\begin{tabular}{|c|c|c|c|c|c|c|c|c|}
\hline$\eta[\mathrm{Pa} \mathrm{s}]$ & 0 & 1 & 10 & 50 & 75 & 100 & 500 & 1000 \\
\hline $\mathrm{E}_{\mathrm{T}(1)}[\mathrm{eV}](5)$ & 11.29 & 11.32 & 11.52 & 12.41 & 12.94 & 13.45 & 19.88 & 26.31 \\
\hline $\mathrm{E}_{\mathrm{T}(2)}[\mathrm{eV}](5)$ & -11.29 & -11.26 & -10.97 & -9.71 & -8.97 & -8.25 & -0.74 & 3.28 \\
\hline $\mathrm{V}_{(1)}[\mathrm{eV}](6)$ & -9.53 & -9.53 & -9.50 & -9.38 & -9.31 & -9.24 & -8.22 & -6.92 \\
\hline $\mathrm{V}_{(2)}[\mathrm{eV}](6)$ & -0.31 & -0.31 & -0.31 & -0.31 & -0.31 & -0.31 & -0.22 & -0.09 \\
\hline $\mathrm{V}_{6}[\mathrm{eV}](8)$ & 0.32 & 0.32 & 0.32 & 0.32 & -0.31 & -0.31 & -0.22 & -0.08 \\
\hline $\mathrm{E}_{6}[\mathrm{eV}](9)$ & 29.22 & 28.80 & 24.97 & 8.82 & 0.54 & 9.33 & 95.61 & 143.64 \\
\hline $\mathrm{KE}_{6}[\mathrm{eV}](10)$ & 150.23 & 150.15 & 149.35 & 145.55 & 143.02 & 140.43 & 107.23 & 91.263 \\
\hline $\mathrm{E}_{\mathrm{T} 6}^{*}[\mathrm{eV}](11)$ & -121.01 & -121.35 & -124.39 & -136.74 & -142.49 & -131.10 & -11.63 & 52.38 \\
\hline$\phi_{1}\left[^{\circ}\right](12)$ & 40.03 & 40.06 & 40.26 & 41.11 & 41.63 & 42.12 & 48.83 & 56.62 \\
\hline$\phi_{6}\left[^{\circ}\right](12)$ & 171.32 & 171.45 & 172.57 & 177.35 & 0.16 & 2.86 & 35.76 & 72.13 \\
\hline $\mathrm{E}_{(2) 6}[\mathrm{eV}](17)$ & -29.48 & -29.05 & -25.22 & -9.06 & 0.30 & 9.10 & 95.40 & 143.42 \\
\hline$\delta[\mathrm{nm}]$ & 1.23 & 1.23 & 1.23 & 1.22 & 1.21 & 1.20 & 1.05 & 0.89 \\
\hline $\mathrm{F}_{\mathrm{AV}}[\mathrm{pN}]$ & 82.38 & 82.36 & 82.14 & 81.18 & 80.60 & 80.02 & 71.40 & 59.35 \\
\hline $\mathrm{E}_{\mathrm{dis}}[\mathrm{eV}](13)$ & 0.00 & 0.06 & 0.56 & 2.70 & 3.97 & 5.20 & 19.13 & 29.59 \\
\hline
\end{tabular}

TABLE II. Numerical values corresponding to the results in Fig. 4. The number of the equation employed is written in brackets in the first column. 
This however does not imply that the interaction becomes gentle by increasing the amplitude of the second mode in bimodal AFM. On the contrary, the tip-sample deformation $\delta$ increases monotonously with increasing $\mathrm{A}_{06}$ (Table I). As dissipation increases however, and for a given $\mathrm{A}_{06}, \delta$ decreases monotonously with increasing $\eta$ and $\mathrm{E}_{\mathrm{dis}}$ (Table II) as in standard AFM. ${ }^{27-29}$ Let us, however, define a modal energy term $E_{(m)}$ similar to that of the frequency term in (9)

$$
E_{(m) n}=K E_{n}+\frac{E_{T(m)} Q_{(m)}}{2 \pi n} .
$$

The numerical values of (17) are shown in Tables I and II for mode $m=2$ and harmonic $n=6$. The sign of $E_{(2) 6}$ is now observed to follow the transitions of $\phi_{6}$ as opposed to the sign of the modal virial $\mathrm{V}_{(2)}$ and the average force $\mathrm{F}_{\mathrm{AV}}$.

In summary, phase contrast in bimodal AFM has been discussed in terms of energy transfer between modes, energy dissipation and the kinetic energy, and energy transfer associated with the harmonic component externally driven at mode 2 and close to resonance, here harmonic 6 . In the simulations here and in the attractive regime where the average force is negative, the single frequency virial remained positive for the two monitored frequencies and the corresponding phase shifts lied above $90^{\circ}$ throughout. On the other hand, in the repulsive regime the single frequency virial, and the corresponding phase shift, might undergo transitions in sign as reported by some. ${ }^{18,19}$ Such transitions might occur even when the average force and the modal virial remain negative. The results should be general for any higher eigenmodes since no assumptions have been made in terms of higher mode number.

The artistic figure was designed by Maritsa Kissamitaki.
${ }^{1}$ T. Rodriguez and R. Garcia, Appl. Phys. Lett. 84(3), 449-551 (2004).

${ }^{2}$ R. Garcia and E. T. Herruzo, Nat. Nanotechnol. 7, 217-226 (2012).

${ }^{3}$ S. D. Solares and G. Chawla, J. Appl. Phys. 108, 054901 (2010).

${ }^{4}$ S. D. Solares and G. Chawla, Meas. Sci. Technol. 21, 125502 (2010).

${ }^{5}$ R. Garcia and R. Proksch, Eur. Polym. J. 49(8), 1897-1906 (2013).

${ }^{6} \mathrm{R}$. Proksch, Appl. Phys. Lett. 89, 113121 (2006).

${ }^{7}$ G. Chawla and S. D. Solares, Appl. Phys. Lett. 99, 074103 (2011).

${ }^{8}$ S. Kawai, T. Glatzel, S. Koch, B. Such, A. Baratoff, and E. Meyer, Phys. Rev. Lett. 103, 220801 (2009).

${ }^{9}$ S. Kawai, T. Glatzel, S. Koch, B. Such, A. Baratoff, and E. Meyer, Phys. Rev. B 81, 085420 (2010).

${ }^{10}$ S. Patil, N. F. Martinez, J. R. Lozano, and R. Garcia, J. Mol. Recognit. 20, 516-523 (2007).

${ }^{11}$ S. Santos, Appl. Phys. Lett. 103, 231603 (2013).

${ }^{12}$ E. T. Herruzo, A. P. Perrino, and R. Garcia, Nat. Commun. 5, 3126 (2014).

${ }^{13}$ D. Forchheimer, D. Platz, E. A. Tholén, and D. B. Haviland, Phys. Rev. B 85, 195449 (2012).

${ }^{14}$ D. Martinez-Martin, E. T. Herruzo, C. Dietz, J. Gomez-Herrero, and R. Garcia, Phys. Rev. Lett. 106, 198101 (2011).

${ }^{15}$ M. D. Aksoy and A. Atalar, Phys. Rev. B 83, 075416 (2011).

${ }^{16}$ E. T. Herruzo and R. Garcia, Beilstein J. Nanotechnol. 3, 198-206 (2012).

${ }^{17}$ R. Stark, Appl. Phys. Lett. 94, 063109 (2009).

${ }^{18}$ D. Kiracofe, A. Raman, and D. Yablon, Beilstein J. Nanotechnol. 4, 385-393 (2013).

${ }^{19}$ I. Chakraborty and D. G. Yablon, Nanotechnology 24(47), 475706 (2013).

${ }^{20} \mathrm{R}$. Steidel, An Introduction to Mechanical Vibrations, 3rd ed. (John Wiley \& Sons, 1989).

${ }^{21}$ J. P. Cleveland, B. Anczykowski, A. E. Schmid, and V. B. Elings, Appl. Phys. Lett. 72(20), 2613-2615 (1998).

${ }^{22}$ A. S. Paulo and R. Garcia, Phys. Rev. B 64, 193411 (2001).

${ }^{23}$ J. R. Lozano and R. Garcia, Phys. Rev. Lett. 100, 076102 (2008).

${ }^{24}$ J. R. Lozano and R. Garcia, Phys. Rev. B 79, 014110 (2009).

${ }^{25}$ R. Garcia and A. San Paulo, Phys. Rev. B 60(7), 4961-4967 (1999).

${ }^{26}$ A. F. Payam, J. R. Ramos, and R. Garcia, ACS Nano 6(6), 4663-4670 (2012).

${ }^{27}$ S. Santos, K. R. Gadelrab, T. Souier, M. Stefancich, and M. Chiesa, Nanoscale 4, 792-800 (2012).

${ }^{28}$ R. Garcia, C. J. Gómez, N. F. Martinez, S. Patil, C. Dietz, and R. Magerle, Phys. Rev. Lett. 97, 016103 (2006).

${ }^{29}$ H. V. Guzman, A. P. Perrino, and R. Garcia, ACS Nano 7(4), 3198-3204 (2013). 